22 Amiel-Tison C, Ellison P. Birth asphyxia in the fullterm newborn: early assessment and outcome. Dev Med Child Neurol 1986;28:671-82

23 Connel J, Oozer R, DeVries L, Dubowitz LMS, Dubowitz V. Continuous EEG monitoring of neonatal seizures: diagnostic and prognostic considerations. Arch Dis Child 1989;64:452-8.

24 Levene MI, Kornberg J, Williams THC. The incidence and severity of post-asphyxial encephalopathy in full term infants. Early Hum Dev 1985;11:21-6.

25 Landis JR, Koch GG. The measurement of observer agreement for categorical data. Biometrics 1977;33:159-74.

26 Ellis M, Manandhar N, Manandhar DS, Costello AM de L. An Apgar score of three or less at one minute is not diagnostic of birth asphyxia but is a useful screening test for neonatal encephalopathy. Indian Pediatr 1988:35:415-21.

27 Parkin JM, Hey EN, Clowes JS. Rapid assessment of gestational age at birth. Arch Dis Child 1976;51:259-63.

28 Makarem A. Principles and technics. In: Henry RJ, Cannon DC, Winkelman JW, eds. Clinical chemistry. Hagerstown, MD: Harper and Row, 1974:1125-47.

29 Reddy V, Shekar M, Rao P, Gillespie S. Nutrition in India. Hyderabad: National Institute of Nutrition, 1992.

30 Badawi N, Kurinczuk JJ, Stanley FJ, Keogh JM, Burton PR. Intrapartum risk factors are important in developing world. [Letter.] BMJ 1999:318:1415

31 Wiswell TE, Bent RC. Meconium staining and the meconium aspiration syndrome. Pediatr Clin North Am 1993;40:955-81.

32 Dijxhoorn MJ, Visser GHA, Fidler VJ, Touwen BCL, Huisjes HJ. Apgar score, meconium and acidaemia at birth in relation to neonatal neurological morbidity in term infants. Br J Obstet Gynaecol 1986;93:217-22.

33 Gaffney G, Sellers S, Flavell V, Squier M, Johnson A. Case-control study of intrapartum care, cerebral palsy, and perinatal death. BMJ 1994;308: $743-50$.
34 Daga AS, Daga SR, Patole SK. Risk assessment in birth asphyxia. J Trop Pediatr 1990;36:34-9.

35 Mahomed K, Mulambo T, Woelk G, Hofmeyr GJ, Gulmezoglu AM. The collaborative randomised amnioinfusion for meconium project (CRAMP): 2. Zimbabwe. Br J Obstet Gynaecol 1998;105:309-13.

36 Hofmeyer GJ. Amnioinfusion for meconium-stained liquor in labour. In Cochrane Library. Issue 1. Oxford: Update Software, 2000.

37 Adamson SJ, Alessandri LM, Badawi N, Burton PR, Pemberton PJ, Stanley F. Predictors of neonatal encephalopathy in full term infants. $B M J$ 1995;311:598-602.

38 Minchom P, Niswander K, Chalmers I, Dauncey M, Newcombe R, Elbourne D, et al. Antecedents and outcome of very early neonatal seizures in infants born at or after term. Br J Obstet Gynaecol 1987;94:431-9.

39 Hannah ME, Hannah WJ, Hellman J, Hewson S, Milner R, Willan A. Induction of labor as compared with serial antenatal monitoring in postterm pregnancy. N Engl J Med 1992;326:1587-92.

40 Yudkin P, Frumar AM, Anderson ABM. A retrospective study of induction of labour. Br J Obstet Gynaecol 1979;86:257-65.

41 Escoffery C, Greenwood R, Ashley D, Coard K, Keeling J, Golding J Deaths associated with intrapartum asphyxia in Jamaica. Paed Perinat Epi dem 1994;8(suppl 1):119-42.

42 Jackson M, Regan C. Elective induction of labor. Clin Obstet Gynecol 1997;40:496-509.

43 Jarvelin MR, Hartikainen-Sorri AL, Rantakallio P. Labour induction policy in hospitals of different levels of specialisation. BrJ Obstet Gynaecol 1993;100:310-5.

44 Laube DW. Induction of labor. Clin Obstet Gynecol 1997;40:485-95.

(Accepted 21 January 2000)

\title{
Prospective cohort study to determine if trial efficacy of anticoagulation for stroke prevention in atrial fibrillation translates into clinical effectiveness
}

\author{
Lalit Kalra, Gloria Yu, Inigo Perez, Anil Lakhani, Nora Donaldson
}

Editorial

by Connolly

Department of Medicine, Guy's, King's, and

St Thomas's School

of Medicine,

London SE5 9PJ

Lalit Kalra

professor of stroke

medicine

Inigo Perez

research fellow

Department of

Medicine for the

Elderly, Bromley

Hospitals NHS

Trust, Orpington

Hospital, Kent

BR6 9JU

Gloria Yu

consultant physician

Department of

Haematology,

Bromley Hospitals

NHS Trust,

Farnborough

Hospital,

Orpington, Kent

BR6 8ND

Anil Lakhani

consultant

haematologist

continued over

BMJ 2000;320:1236-9

\begin{abstract}
Objective To determine whether trial efficacy of prophylaxis with warfarin for patients with atrial fibrillation at high risk of stroke translates into effectiveness in clinical practice.

Design Two year prospective cohort study. Setting District general hospital.
\end{abstract}

Participants 167 patients with atrial fibrillation and at high stroke risk who were eligible for anticoagulation. Interventions Long term anticoagulation with warfarin at adjusted doses to maintain an international normalised ratio of 2.0-3.0.

Main outcome measures Comparison of patient characteristics, comorbidity, anticoagulation control, stroke rate, and haemorrhagic complications with pooled data from five randomised controlled trials. Results Patients in the study group were seven years older (95\% confidence interval 4 to 10$)$ and comprised 33\% more women than patients in the pooled trials. The international normalised ratio was in the target range for $61 \%$ of the time (range $37 \%-85 \%$ ), below for $26 \%$ of the time (range $8 \%-32 \%$ ), and above for $13 \%$ of the time (range $6 \%-26 \%$ ). The time that patients in the study group spent in the target range was significantly less than in the pooled analysis. The incidence of stroke in the study group $(2.0 \%$ per year, $0.7 \%$ to $4.4 \%)$ was comparable to that of patients receiving warfarin in pooled studies $(1.4 \%$, $0.8 \%$ to $2.3 \%)$. Per year the incidence of major $(1.7 \% v$
$1.6 \%)$ and minor $(5.4 \%$ v $9.2 \%)$ bleeding complications was also similar.

Conclusion Rates of stroke and major haemorrhage after anticoagulation in clinical practice were comparable to those obtained from pooled data from randomised controlled studies for patients with atrial fibrillation at high risk of stroke.

\section{Introduction}

Many randomised controlled studies have shown the effectiveness of anticoagulation in preventing stroke in patients with atrial fibrillation. ${ }^{1-7}$ Furthermore, clinical guidelines have been developed to identify patients at high risk who will benefit most from this intervention. $^{8-11}$ Recent studies have, however, shown that anticoagulation is underused in clinical practice. ${ }^{12-16}$

Several reasons have been given for the low rate of anticoagulation in eligible patients with atrial fibrillation. Major randomised trials were considered unrepresentative of clinical practice because only a small percentage of screened patients were included, and the proportion of men and younger patients was higher than expected in community settings. ${ }^{15}$ A reanalysis of pooled data showed that the benefits of anticoagulation may have been overestimated, ${ }^{17}$ and there seemed to be little absolute reduction in stroke rates with anticoagulation in patients with atrial fibrillation unselected for stroke risk. ${ }^{18}$ Additionally, a retrospective review of case notes concluded that the extent of anti- 
coagulation control, therapeutic efficacy, and low complication rates in randomised trials were not matched in clinical practice. $^{19}$ Despite the evidence from randomised trials, there was little proof that anticoagulation in atrial fibrillation would have the desired effect in clinical practice.

We aimed to compare personal characteristics, anticoagulation control, and outcome in patients who were at high risk of stroke and receiving anticoagulation in clinical practice with those of patients in randomised controlled trials.

\section{Participants and methods}

\section{Participants}

We recruited patients with chronic non-valvular atrial fibrillation under the age of 90 years from general medical clinics in a district general hospital. We excluded those already receiving warfarin for atrial fibrillation or other indications (for example, pulmonary emboli, deep vein thrombosis).

Diagnosis was confirmed by electrocardiography, and patients were assessed for the cause and duration of atrial fibrillation, vascular risk factors, risk of bleeding complications, and comorbidity or other drugs that may influence anticoagulant use. ${ }^{16}$ Stroke risk was assessed with clinical and echocardiographic criteria derived from randomised trials, and only patients at high risk were included. Clinical criteria were age over 75 years, history of transient ischaemic attack or a non-disabling stroke at least six months before assessment, and any of previous thromboembolism, hypertension, diabetes mellitus, or congestive heart failure. ${ }^{9}$ Echocardiographic criteria included a left atrium dimension greater than $2.5 \mathrm{~cm} / \mathrm{m}^{2}$, focal abnormalities in movement of the left ventricular wall, cardiomyopathy (global dyskinesia with left ventricular ejection fraction less than $40 \%$ ), and intracardiac thrombus. ${ }^{20}$

Major contraindications to anticoagulation were gastrointestinal or genitourinary bleeding in the past six months, coagulation defects, thrombocytopenia, haemorrhagic stroke, excessive alcohol intake, dementia, recurrent falls, and poor drug or clinic compliance. $^{1-5}$ We included patients already taking aspirin, but it was discontinued during the study.

\section{Anticoagulation practice}

Eligible patients were managed by the local anticoagulation services according to local guidelines. The target range for anticoagulation was an international normalised ratio of 2.0-3.0 using adjusted warfarin doses. Blood was taken by phlebotomists in outpatients, and the dose of warfarin was advised by doctors unaware of patients' participation in the study. Monitoring and dose adjustment were at the discretion of the anticoagulation services. The number of blood tests and the results were recorded after induction when the international normalised ratio was stabilised within the target range. The number of days when the international normalised ratio was in the target range was calculated by adding the number of days after the measurement of ratios in the range 2.0-3.0 and a subsequent value out of this range. Patients discontinuing warfarin for more than four weeks were treated as withdrawals.

\section{Follow up}

All patients were followed up for two years and reviewed every six months by a doctor unaware of their international normalised ratio values. Patients were assessed for neurological status, episodes of bleeding and intercurrent illness, or changes in drugs that may influence anticoagulation control. Hospital records were consulted to document admissions or events that may not have been recalled by the patient, and further information was obtained from general practice and community sources. Patients who did not attend for appointments were contacted by the research team. This strategy enabled 100\% completion of all follow up assessments.

\section{End points and statistical analyses}

To maintain consistency with the meta-analysis of pooled data we used ischaemic stroke confirmed by computerised tomography as the primary outcome measure for comparison. We made no distinction between cardioembolic stroke or ischaemic stroke due to other causes. Intracerebral haemorrhages were counted as bleeding complications. The diagnosis of transient ischaemic attacks was based on clinical criteria, ${ }^{21}$ and the number of episodes in the study group was recorded. All deaths were recorded and a cause assigned on the basis of available clinical information. Deaths due to cerebrovascular causes were excluded to prevent double counting. All bleeding events were recorded. Major bleeding was defined as intracranial haemorrhage, fatal bleeding, or bleeding leading to admission to hospital, emergency procedures, or urgent transfusion. All other bleeds were classified as minor.

We used two sample confidence intervals for the difference of means and proportions to compare important prognostic variables between randomised trials and the current sample. Additionally, we assessed the size of the differences in the individual clinical trials using Tukey's correction after analysis of variance. We calculated the event rate per patient year, and the exact Poisson confidence intervals were used for comparisons of clinical outcomes because of the small numbers (due to low incidence) in these groups.

\section{Results}

\section{Patient characteristics}

Chronic atrial fibrillation was confirmed by electrocardiography in 344 (14\%) of the 2457 patients. The median time between the first diagnosis of atrial fibrillation and research assessment was 17.5 months (range 2-34 months). A high risk of stroke on the basis of clinical or echocardiographic criteria was present in 286 of $344(83 \%)$ patients, $38(13 \%)$ of whom had major contraindications to anticoagulation. Of the 248 patients eligible for anticoagulation, warfarin was already being given to 76 (31\%), and five refused anticoagulation. We recruited the remaining 167 patients to the study.

The mean age of patients in the study was 76.6 (SD 11.2 ) years, and $58 \%$ were women. Patients in the study group were on average seven years older and comprised 33\% more women than those in the pooled analysis (table 1). Although the proportions of patients with hypertension and diabetes mellitus were
Biostatistics Unit, Research and Development Department, King's College Hospital, London SE5 9RS

Nora Donaldson senior lecturer

Correspondence to: L Kalra

lalit.kalra@kcl.ac.uk 
Table 1 Clinical characteristics of patients in clinical study compared with pooled data from five major randomised controlled trials of patients receiving warfarin. Values for pooled data are percentages unless stated otherwise

\begin{tabular}{lccc} 
& Clinical practice & Pooled data $^{7}$ & Difference (95\% Cl) \\
\hline Mean age (years) & 77 & 69 & $7(4 \text { to } 10)^{*}$ \\
\hline No (\%) & & & \\
\hline$<75$ years & $87(52)$ & 80 & $-28(-36$ to -20$)$ \\
\hline$>75$ years & $80(48)$ & 20 & $28(20$ to 36$)$ \\
\hline Men & $70(42)$ & 75 & $-33(-41$ to -25$)$ \\
\hline Hypertension & $72(43)$ & 45 & $-2(-10$ to 6$)$ \\
\hline Diabetes mellitus & $25(15)$ & 13 & $2(-4$ to 8$)$ \\
\hline Current smokers & $22(13)$ & 12 & $1(-4$ to 6$)$ \\
\hline $\begin{array}{l}\text { Previous stroke or transient } \\
\text { ischaemic attack }(>6 / 12)\end{array}$ & $23(14)$ & 6 & $8(3$ to 13$)$ \\
\hline $\begin{array}{l}\text { Congestive heart failure } \\
\text { Ischaemic heart disease }\end{array}$ & $33(20)$ & 20 & $0(-6$ to 6$)$ \\
\hline
\end{tabular}

comparable between the study group and pooled data, the study group had a significantly higher proportion of patients with previous stroke or transient ischaemic attack and a significantly lower proportion of patients with ischaemic heart disease (table 1).

\section{Quality of anticoagulation}

Treatment with warfarin was stopped in $30(18 \%)$ study patients during follow up (table 2). Reasons included death (eight patients), major bleed (four), intracranial haemorrhage (one), disabling stroke (three), patients' choice (eight), poor compliance (four), and interactions with other drugs (two). No correlation was found between age, sex, frequency of blood tests, and duration of anticoagulation and stopping warfarin. The proportion of patients stopping treatment because of bleeding complications ( $2 \%$; four patients) was no greater than in clinical trials $(1.4 \%$ to $6 \%) .{ }^{13}$

Blood tests for monitoring anticoagulation were undertaken less frequently in the study group than in the clinical trials. The interval between tests in the study group varied considerably: 20\% were less than 21 days,

Table 2 Anticoagulation practice and quality of control

Trial

\begin{tabular}{lccccccc}
\cline { 3 - 7 } & $\begin{array}{c}\text { Clinical } \\
\text { practice }\end{array}$ & $\begin{array}{c}\text { Peterson } \\
\text { et al }^{1}\end{array}$ & $\begin{array}{c}\text { Boston } \\
\text { area }^{2}\end{array}$ & $\begin{array}{c}\text { Stroke } \\
\text { prevention }^{3}\end{array}$ & $\begin{array}{c}\text { Connolly } \\
\text { et al }^{4}\end{array}$ & $\begin{array}{c}\text { Ezekowitz } \\
\text { et al }^{5}\end{array}$ & $\begin{array}{c}\text { Pooled } \\
\text { data }\end{array}$ \\
\hline Target range (INR & $2.0-3.0$ & $2.4-4.2$ & $1.5-2.7$ & $2.0-4.5$ & $2.0-3.0$ & $1.4-2.8$ & Variable
\end{tabular}
equivalent)

\begin{tabular}{llllllll}
\hline Interval between tests & 31 & 28 & 21 & 30 & 21 & 30 & $21-30$
\end{tabular}

(days) $^{*}$

\begin{tabular}{llllllll}
$\%$ time spent in range & 61 & 73 & 83 & 71 & 44 & 56 & 66 \\
\hline
\end{tabular}

\begin{tabular}{llllllll}
\hline$\%$ time below target range & 26 & 26 & 8 & 23 & 40 & 29 & 25 \\
\hline
\end{tabular}

$\begin{array}{llllllll}\% \text { time above range } & 13 & 1 & 9 & 5 & 16 & 15 & 9\end{array}$

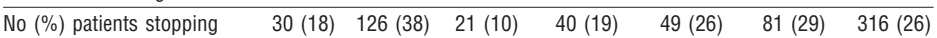
warfarin

*After initial period of stabilisation of international normalised ratio values, during which more frequent sampling was undertaken. Interval between tests includes tests for routine monitoring and more frequent repeat testing when values are outside range.

Table 3 Annual events in patients taking warfarin

\begin{tabular}{|c|c|c|c|c|}
\hline & \multicolumn{2}{|c|}{ Clinical practice } & \multicolumn{2}{|c|}{ Pooled data } \\
\hline & $\begin{array}{l}\text { No of } \\
\text { events }\end{array}$ & $\begin{array}{c}\text { Annual event rate } \\
(95 \% \mathrm{Cl})\end{array}$ & $\begin{array}{l}\text { No of } \\
\text { events }\end{array}$ & $\begin{array}{c}\text { Annual event rate } \\
(95 \% \mathrm{Cl})\end{array}$ \\
\hline Ischaemic stroke & 6 & $2.0(0.7$ to 4.4$)$ & 26 & $1.4(0.8$ to 2.3$)$ \\
\hline Transient ischaemic attack & 3 & $1.0(0.1$ to 4.0$)$ & 13 & $0.7(0.3$ to 1.4$)$ \\
\hline Death from non-cerebral causes & 7 & $2.4(0.6$ to 6.1$)$ & 69 & $3.6(2.7$ to 4.9$)$ \\
\hline Intracranial haemorrhage & 1 & 0.3 (0.03 to 2.7$)$ & 5 & $0.3(0.06$ to 0.7$)$ \\
\hline Major bleeding & 4 & $1.4(0.2$ to 4.6$)$ & 24 & $1.3(0.7$ to 2.1$)$ \\
\hline Minor bleeding & 16 & $5.4(2.4$ to 10.2$)$ & 150 & 9.2 (3.7 to 12 ) \\
\hline
\end{tabular}

$47 \%$ were between 21 and 28, 23\% were between 29 and 42, and $10 \%$ were greater than 42 . The international normalised ratio for patients in the study group was in the target range for an average of $61 \%$ of the time (range $37 \%-85 \%$ ), below for $26 \%$ of the time $(8 \%-32 \%)$, and above for $13 \%$ of the time $(6 \%-26 \%)$ (table 2). The time spent in the target range in the study group was significantly less than in the pooled trials (difference $4 \%, 95 \%$ confidence interval $2 \%$ to $8 \%$ ).

\section{End points}

All surviving patients were monitored for the planned duration, resulting in 313 patient years of follow up, during which they received warfarin for 296 patient years. Six patients in the study group had ischaemic strokes (three cardioembolic, two indeterminate, one small vessel); one died (table 3). Only one of the six cases of infarct occurred during adequate anticoagulation (international normalised ratio 2.6). Two patients who had withdrawn from treatment had strokes (12 and 44 weeks after warfarin was stopped), and three patients had international normalised ratios below the target range. Two of the three patients with transient ischaemic attack had international normalised ratios in the target range; warfarin had been discontinued for three weeks at one patient's request and was restarted after the event. Seven patients died due to non-cerebral causes: two from myocardial infarction, one from sudden death (vascular), and three from unrelated causes.

One patient with an international normalised ratio of 6.9 had an intracranial haemorrhage. Four other patients had major bleeds: two patients required surgery for massive rectal bleeding owing to undiagnosed carcinoma of the colon (international normalised ratio 2.0-3.0), one received a transfusion for haematemesis (2.3), and one received a transfusion for melaena (1.6). Sixteen patients $(5.4 \%)$ had minor bleeding episodes: epistaxis (five patients), bruising (four), rectal bleeding (three), haematuria (three), and haemarthrosis (one). Warfarin was stopped temporarily (for less than four weeks) in these patients. Seven patients had international normalised ratios greater than 5.0 (range 5.2-10.3) without any bleeding complications, and after adjustment of warfarin dose these were within the target range.

The annual event rate for stroke in patients in the study group $(2.0 \%, 95 \%$ confidence interval $0.7 \%$ to $4.4 \%$ ) was higher than that of patients in the pooled analysis who had received anticoagulation $(1.4 \%, 0.8 \%$ to $2.3 \%$ ), but this difference was not statistically significant (table 3). The annual event rate for major bleed (including intracerebral haemorrhage) in patients in the study group $(1.7 \%, 0.5 \%$ to $3.9 \%)$ was also not significantly different from that of patients in the pooled analysis $(1.6 \%, 0.7 \%$ to $2.1 \%)$.

\section{Discussion}

Patients in the clinical study were older, consisted of more women, and spent significantly less time in the target anticoagulation range than patients in the pooled data from randomised trials. Despite these differences, the rates for stroke and major haemorrhage in the study group were comparable to those in the pooled data. The efficacy of warfarin in preventing 
stroke in trial conditions therefore translates into effectiveness in clinical practice for patients at high risk.

To ensure that we chose patients who were comparable to those at high risk of stroke receiving warfarin in randomised studies we made our selection on the basis of criteria derived from randomised trials. We excluded patients who had had a stroke up to six months before the study so that primary and not secondary prevention was being assessed. We conducted our study prospectively to ensure that all withdrawals, anticoagulation deviations, events, and complications were identified. Patients already taking anticoagulants were excluded to ensure that early withdrawals did not bias results in favour of anticoagulation. Recall bias for events, especially transient ischaemic attack or minor bleeds, was prevented by depending not only on patients' memory for events during structured interviews but also by reviewing hospital records and information from general practice sources.

Representativeness was addressed by recruiting patients from general medical clinics and including only those at high risk as these were the patients most likely to receive anticoagulation in clinical practice. In this group there is firm evidence of the superiority of anticoagulation over aspirin ${ }^{1-7}$ compared with those at lower risk, where controversy about best clinical practice exists. ${ }^{102}$ As anticoagulation was undertaken by staff unaware of patients' participation in the study, it is likely that the findings reflect anticoagulation practice in service settings. Blood testing for anticoagulation control was less frequent in clinical practice than in randomised studies, and patients spent significantly less time in the target anticoagulation range. These differences may be clinically relevant as three of the six strokes occurred in patients in whom the international normalised ratio was less than 2.0. Although patients in the study group spent $13 \%$ of time above the target range, the frequency of bleeding complications did not exceed that seen in clinical trials.

Long term anticoagulation with adjusted warfarin dose should be considered in all patients eligible for warfarin with atrial fibrillation who are at high risk of thromboembolism, especially as studies have shown that aspirin or fixed low doses of warfarin have limitations. ${ }^{62}{ }^{24}$ The case for wider but judicious use of anticoagulation is strengthened by this study, which shows that anticoagulation for stroke prevention is feasible, safe, and effective in clinical practice, even in elderly people.

Contributors: LK had the original idea, designed, initiated, and coordinated the study, and was responsible for data analysis, interpretation, and writing the paper. GY discussed core ideas and participated in the protocol design, data collection, and data analysis. IP initiated research and was involved with patient assessments, data collection, and extraction of data from major trials and their analysis. AL discussed core ideas, provided haematology input, initiated research, and participated in data collection, particularly on anticoagulation. ND discussed core ideas, provided statistical guidance, participated in analysis and interpretation of pooled data from randomised studies, undertook comparative analyses, and contributed to the paper. LK, GY, and AL will act as guarantors for the paper.

Funding: IP is supported by a grant from the NHS Research and Development Health Technology Assessment Programme.

Competing interests: None declared.

\section{What is already known on this topic}

Anticoagulation with adjusted warfarin dose in patients with atrial fibrillation consistently reduces the risk of stroke by two thirds at the small risk of major bleeding complications

Despite evidence in the published literature, anticoagulation is underused in clinical practice because it is not known whether trial efficacy translates into clinical practice

\section{What this study adds}

Stroke and haemorrhage rates were comparable to those in randomised studies despite significant differences in patient characteristics and anticoagulation control in clinical practice

1 Peterson P, Boyson G, Godtfredsen J, Andersen ED, Andersen B on behalf of the Copenhagen Atrial Fibrillation Aspirin Anti-Koagulation Study Group. Placebo-controlled randomised trial of warfarin and aspirin for prevention of thromboembolic complications in chronic atrial fibrillation. Lancet 1989·: $175-89$.

2 Boston Area Anticoagulation Trial for Atrial Fibrillation (BAATAF) Investigators. The effect of low dose warfarin on the risk of stroke in patients with non rheumatic atrial fibrillation. $N$ Engl J Med 1990; 323:1505-11.

3 Stroke Prevention in Atrial Fibrillation (SPAF) Investigators. Stroke prevention in atrial fibrillation study: final results. Circulation 1991;84:527-39.

4 Connolly SJ, Laupacis A, Gent M, Roberts RS, Cairns JA, Joyner C. Canadian atrial fibrillation anticoagulation (CAFA) study. J Am Coll Cardiol 1991;18:349-55.

5 Ezekowitz MD, Bridgers SL, James KE, Carliner NH, Colling CL, Gornick CC, et al. Warfarin in the prevention of stroke associated with nonrheumatic atrial fibrillation. (SPINAF). N Engl J Med 1992;327:1406-12.

6 SPAF Investigators. Adjusted dose warfarin versus low intensity fixed dose warfarin plus aspirin for high risk patients with atrial fibrillation. Lancet 1996;348:633-8.

7 Atrial Fibrillation Investigators. Risk factors for stroke and efficacy of antithrombotic treatment in atrial fibrillation: analysis of pooled data from five randomised controlled studies. Arch Intern Med 1994;154:1449-57.

8 Matchar DB, McCroy DC, Barnett HJM, Feussner JR. Guidelines fo medical treatment for stroke prevention. Ann Intern Med 1994;121:54-5.

9 Laupacis A, Albers G, Dalen J, Dunn M, Feinberg W, Jacobson A Antithrombotic therapy in atrial fibrillation. Fourth ACCP consensus conference on antithrombotic therapy. Chest 1995;108 (suppl 4):352-9S.

10 Lip GY, Lowe GD. ABC of atrial fibrillation. Antithrombotic treatment for atrial fibrillation. BMJ 1996;312:45-9.

11 Feinberg WM. Anticoagulation for prevention of stroke. Neurology 1998;51(suppl 3):20-2S.

12 Albers GW, Yim JM, Belew KM, Bittar N, Hattemer CR, Phillips BG, et al. Status of antithrombotic therapy for patients with atrial fibrillation in university hospitals. Arch Intern Med 1996;156:2311-6

13 Whittle J, Wickenheiser L, Venditti LN. Is warfarin being underused in the treatment of elderly persons with atrial fibrillation? Arch Intern Med 1997;157:451-5.

14 Brass LM, Krumholz HM, Scinto JM, Radford M. Warfarin use among patients with atrial fibrillation. Stroke 1997;28:2382-9

15 Sudlow M, Thomson R, Thwaites B, Rodgers H, Kenny RA. Prevalence of atrial fibrillation and eligibility for anticoagulants in the community. Lancet 1998;352:1167-71.

16 Kalra L, Perez I, Melbourn A. Risk assessment and anticoagulation for primary stroke prevention in atrial fibrillation. Stroke 1999;30:1218-22.

17 Green CJ, Hadorn DC, Bassett K, Kazanjian A. Anticoagulation in chronic non-valvular atrial fibrillation: a critical appraisal and meta-analysis. Can J Cardiol 1997;13:811-5.

18 Stroke Prevention in Atrial Fibrillation Group. Warfarin versus aspirin for prevention of thromboembolism in atrial fibrillation: stroke prevention in atrial fibrillation II study. Lancet 1994;343;687-91.

19 Gottlieb LK, Salem SS. Anticoagulation in atrial fibrillation: does effectiveness in clinical trials translate into effective practice? Arch Intern Med 1994;154:1945-53.

20 The Stroke Prevention in Atrial Fibrillation Investigators. Predictors of thromboembolism in AF: echocardiographic features of patients at risk Ann Intern Med 1992;116:6-12.

21 Sandercock PAG. Recent developments in the diagnosis and management of patients with transient ischaemic attacks and minor ischaemic strokes. OJ Med 1991;286:101-12

22 Hellemons BSP, Langenberg H, Lodder J, Vermeer F, Schouten HJA, Lemmens T, et al. Primary prevention of arterial thromboembolism in non-rheumatic atrial fibrillation: randomised controlled trial comparing two intensities of coumarin with aspirin. BMJ 1999;319:958-64.

23 Aronow WS, Ahn C, Kronzon I, Gutstein H. Incidence of new thromboembolic stroke in persons 62 years and older with chronic atrial fibrillation treated with warfarin versus aspirin. J Am Geriatr Soc 1999;47:366-8. Goefoed BG, Petersen P, Pedersen TS, Andersen ED, Godtfredsen J, et al. Fixed minidose warfarin and aspirin alone and in combination vs adjusted dose warfarin for stroke prevention in atrial fibrillation: second Copenhagen atrial fibrillation, aspirin and anticoagulation study. Arch Intern Med 1998;158:1487-91.

(Accepted 21 January 2000) 